\title{
Thinking about the Characteristic Development of Product Design Major under the Guidance of Emerging Engineering Education
}

\author{
WANG Li $^{1}$, ZHANG Hai-chao ${ }^{1}$, WANG Qiang ${ }^{2}$ \\ 1 Dalian Institute of Science and Technology China \\ 2 Dalian Jiaotong University, China
}

\begin{abstract}
In the face of a new round of scientific and technological revolution and industrial transformation, the construction of emerging engineering education has become a hot trend, which brings new opportunities and challenges to the development of characteristic development of the product design major. Combining with the teaching reform of the product design major in Dalian Institute of Science and Technology, this paper probes into the teaching reform from the aspects of knowledge structure, teaching organization form, core curriculum construction, teaching method and cooperative development with other majors in order to promote characteristic development of the product design major.
\end{abstract}

Keywords-Emerging engineering education; Product design; Transformation of education; Core curriculum

\section{INTRODUCTION}

With the demand of national innovation-driven development strategy, the transformation of social industry changes rapidly. The national strategic demand, such as "made in China 2025", "Internet" plus "artificial intelligence" and so on, is changing rapidly. It drives a new round of scientific and technological revolution and industrial reform, and puts forward new requirements for engineering education. In 2017, the Ministry of Education issued the notice of the Department of higher Education of the Ministry of Education on the development of "emerging engineering education" research and practice, and the "notice on the promotion of emerging engineering education research and practice projects", introducing the concept of "emerging engineering education" for the first time. Colleges and universities are required to vigorously carry out emerging engineering education. There is no clear definition of emerging engineering education, but there is a consensus on the scope of emerging engineering education [1-2]. It mainly includes the "Internet plus", big data, artificial intelligence, intelligent manufacturing, robotics, cloud computing, as well as the upgrading of traditional engineering major.

Dalian Institute of Science and Technology joined the Emerging Engineering Education Alliance in March 2018. Our university will build up the educational concept in line with the development of "Emerging Engineering Education" and turn Dalian Institute of Science and Technology into a university of "Emerging Engineering Education" applied talents training [3-4].

Based on the above background, and in order to adapt to the demand of design talents for the development of industry in the new era, the specialty of product design must constantly adjust the knowledge system and the teaching content, and closely combine the new ideas, new structures and new models of the emerging engineering education. The course of design college should be dominated by practical application. The connotation of the whole specialty is changing from the original form design, the engineering design to the user experience and service. And the digitization and intelligence in the emerging engineering education can be applied in the product design very well. Intelligent products and equipment are the strategic of our country. At present, there is a great lack of intelligent manufacturing equipment and intelligent service robot in the teaching of industrial design. These are the important research objects of product design, and the current curriculum system is short of such content.

At present, the theories, methods and models of product design education under the guidance of emerging engineering education are still scarce and are just beginning. In view of the above, this article has made the following considerations to the product design specialty education reform:

\section{The Changes of TeAching KNOWLEDGE StRUCTURE}

In the traditional sense, the specialty of product design is more inclined to the design of product modeling, so that the whole society understands product design as applied art, and the cultivation of design expression ability and design thinking has always been the most important part of talent training. The product design profession emphasizes the cultivation of innovation consciousness, needs to have acuteness of observation and potential exploration and creativity in the future .

But from the current development trend of product design subject, digitization and intelligence, as well as service design consciousness, have promoted the development of product design specialty. Especially about intelligent product, intelligent manufacturing equipment, intelligent service robot and so on, are the important research objects of product design, 
but the current talent training plan lacks this teaching link and content.

From the current development of the emerging engineering education. Artificial intelligence and cognitive science, intelligent design and digital manufacturing, big data visualization and virtual reality, design knowledge management and decision-making, emotional computing and virtual reality, service design and social innovation, computer aided design and 3D printing knowledge structure should be added to product design education.

In the face of the development of industry transformation, product design has changed from traditional creation design to design service, from focusing on product function to paying attention to user experience, so future industrial design will be more integrated with service design, user experience and artificial intelligence and other aspects. Therefore, the knowledge structure of product design has changed greatly.

To sum up, in the future industrial design education, we should vigorously promote product design plus cognitive science, industrial design plus swarm intelligence, industrial design plus big data visualization, industrial design plus artificial intelligence, Industrial design plus intelligent service robot, industrial design plus material augmentation manufacturing and so on. These research directions will become the new research field and new growth point of industrial design education under the emerging engineering education background.

\section{Changes of PROduct Design TALENT TRAINING UNDER EMERGING ENGINEERING EDUCATION}

The development of emerging engineering education puts forward new opportunities and challenges for product design talents training. From the point of view of knowledge and ability. First of all, knowledge mainly includes solid basic knowledge and profound professional knowledge, selflearning ability and the view of globalization. Secondly, the ability includes cross-disciplinary integration, communication and coordination, design organization and management.

In terms of design knowledge, from design form, design semantics to user investigation and analysis, the students' ability of data analysis and logic analysis should be strengthened, as well as the understanding and mastery of relevant knowledge of product design user experience.

In terms of design knowledge, from design form, design semantics to user investigation and analysis, the students' ability of data analysis and logic analysis should be strengthened, as well as the understanding and mastery of relevant knowledge of product design user experience.

\section{SySTEM CONSTRUCTION OF TEACHING ORGANIZATION FORMS}

The teaching organization form of product design specialty is mainly to construct the course system of the specialty. The organization form of the product design specialty course basically revolves around three levels: design modeling and expression, design thinking and method, design culture and commerce. The organization of carrying out teaching step by step.

In addition, in order to achieve the optimal development of teaching organization, two aspects are divided: 1 . The establishment of curriculum principal system, focusing on the construction of curriculum content and optimizing the rationality and final effect of curriculum will help teachers master the purpose of mastering 2-3 main courses. 2. Establish curriculum group system, such as professional basic curriculum group, design and culture curriculum group, design and engineering curriculum group, user and business curriculum group, so as to classify curriculum group, strengthen the awareness of curriculum content and strengthen teachers' research on the depth of the problem.

\section{THE CONSTRUCTION OF PROFESSIONAL CHARACTERISTICS IS THE CONSTRUCTION OF CORE CURRICULUM}

The key point of specialty construction of product design is the construction of core curriculum, and the development direction of core curriculum is the focus of talent training, even the employment orientation of students after graduation. The development of the core curriculum will be based on the advantages of the school's regional resources, local industrial characteristics, regional cultural patterns, and the development characteristics of the school, and so on.

Based on the above background, the characteristics of product design and industrial design are mainly reflected in the following aspects: 1 . The new aesthetics, new materials and new craft influence the life style of the development of the life product of the innovation of culture. 2. Brand culture and commerce; 3 . The commercial design and innovation of Internet thinking; 4. Intelligent and human-computer interaction technology application (entity interaction); 5. The experience and service of healthy life design;

\section{Changes in Teaching Methods}

In order to meet the needs of emerging engineering education, product design education should be studentcentered. By introducing PBL teaching method, teachers can change from "knowledge educator" to "knowledge leader" and realize the new training mode of "student-centered".

In addition, we should devote great efforts to the use of modern information technology means, using online courses or virtual digital ways to build an integrated platform for the teaching of information technology and product design specialty, and to build an incubator base. Let students carry out innovative and entrepreneurial activities in the field of design, promote the development of industry, college and 
research, so that product design education can be closely linked with the design industry and the market.

\section{SYNERGISTIC DEVELOPMENT WITH OTHER MAJORS}

The product design major strengthens the cooperation with the industrial design and animation design major of our college. Strengthen the cooperation and cooperation between students through the course link of cross and practice.

(1)To strengthen the learning and application of new knowledge and new fields, especially the intervention of design tools and methods. Strengthen the advantages of product design and industrial design, such as innovation consciousness of product design, technical realization of industrial design, etc.

(2) Strengthen cross-disciplinary cooperation with different majors in other faculties, especially in crosscurriculum and practice. For example, design plus business, design plus Internet of things, design plus engineering can not only arrange different professional teachers to teach together, but also can set up high-level design center. So that the practice platform open to the whole school, encourage everyone to communicate with each other.

(3)To strengthen the diversity of teaching staff, especially the introduction of teachers with strong ability of application and practice, to complement and develop with the original teaching staff, and to form a comprehensive teaching team in line with the special development of specialty.

(4)To strengthen the construction of the construction practice teaching platform, the development and change of new science and technology, new engineering, new materials and processing technology are always concerned, so that the laboratory can not only guarantee the smooth development of the practice teaching link, but also strengthen the development of the laboratory with the core technology advantage.
(5)Art majors in product design should also continue to maintain a humanistic perspective to explore the combination of culture, creativity and commerce, plus the industrial design of engineering, so as to bring into play the technical support advantages of the industrial design profession. In particular, intelligent and interactive technology implementation and other aspects of the characteristics.

\section{CONCLUSION}

The development of artificial intelligence and big data has subverted the knowledge form of traditional engineering, and the concept of product design education is changing accordingly. In order to adapt to the upgrading of Chinese intelligence, under the background of emerging engineering education, product design education should also cultivate compound design talents with the combination of new course science and new engineering and art. The specialty of product design in Dalian Institute of Science and Technology still needs to accumulate and develop in the aspects of specialty construction, teacher development and teaching management, in order to find its own professional characteristics.

\section{REFERENCES}

[1] Li Hua, Hu Na, You Zhengsheng. New engineering education: Form, connotation and orientation [J]. Research on higher Engineering Education, 2017( 4): 16 - 19

[2] Deng Rong. Thinking about the characteristic Development of Product Design and Industrial Design Teaching Specialty [J]. Design,2017.(12): 118-120.

[3] Wu Lei. Teaching methods and practice of Industrial Design Specialty under the idea of New Engineering subject $[\mathrm{J}]$. Higher architecture and education, 2018,(27):10-13.

[4] Zhou Rui, Fei Lingfeng. Exploration of CDIO Model of Industrial Design Engineering Education based on practical Project system [J]. Journal of Engineering Design, 2013,20 (2): 151-156. 